\title{
DECISÕES JUDICIAIS: DIAGNÓSTICO E PROPOSTAS PARA UMA TEORIA DA DECISÃO DEMOCRATICAMENTE CONSTRUÍDA
}

Judicial Decisions: diagnosis and proposals for a democratically constructed Decision Theory

\section{Maicon Crestani}

maicrestani@gmail.com

Afiliação: Unisinos, RS

Doutorando em Direito Público - Unisinos

\section{RESUMO}

Este trabalho busca compreender como ocorre o processo de tomada de decisões no Direito brasileiro, tendo como pressuposto a importância dos paradigmas filosóficos para essa análise. Com base nos aportes da Crítica Hermenêutica do Direito, busca-se, mediante um recorte da legislação pertinente, apresentar possíveis leituras de textos legais que são centrais para a tomada de decisão judicial. Nesse sentido, o trabalho é desenvolvido da seguinte forma: primeiramente, tecemos considerações acerca da importância dos paradigmas filosóficos para a compreensão do papel das decisões judiciais no âmbito do Direito. Após, é apresentada a forma como as decisões judiciais são proferidas no caso brasileiro. Por fim, destaca-se a importância de específicos textos legais sobre a temática.

Palavras-chave: Decisão judicial. Democracia. Teoria da decisão judicial. Paradigma filosófico. Crítica Hermenêutica do Direito.

\section{ABSTRACT}

This paper seeks to understand how the decision-making process in Brazilian Law occurs, assuming the importance of philosophical paradigms for this analysis. Based on the contributions of the Hermeneutical Critique of Law, it is intended, through a cut of the pertinent legislation, to present possible readings of legal texts that are central to judicial decision-making. In this sense, the work is developed as follows: first, considerations are made about the importance of philosophical paradigms for the understanding of the role of judicial decisions. Then, the way in which the judicial decisions are rendered in the Brazilian case is presented. Finally, the importance of specific legal texts on the subject is highlighted.

Keywords: Judicial Decision. Democracy. Theory of Judicial Decision. Philosophical Paradigm. Hermeneutical Critique of Law.

\section{INTRODUÇÃO}

Dentro de uma concepção de Estado Democrático de Direito, a necessidade de uma Teoria da Decisão se impõe como central, porquanto verdadeira condição de possibilidade para a concretização da democracia. A questão fundamental é que a decisão judicial não deve ser encarada apenas como um ato de vontade, numa perspectiva positivista por assim dizer, mas sim como parte essencial do processo e que, justamente por isso, deve ser democraticamente controlada. É a partir dessa premissa que se pretende desenvolver o presente trabalho. 
Necessariamente, deve ser apresentado um quadro acerca da natureza das decisões judiciais respeitante ao caso brasileiro, no sentido de demonstrar, num aspecto qualitativo, como ocorre a atividade jurisdicional decisória. Dessa forma, necessário igualmente a indagação a respeito dos paradigmas de fundo que subjazem a esta atividade.

O objetivo deste trabalho é demonstrar a relação e a importância dos paradigmas filosóficos sobre o tema das decisões jurídicas e apresentar algumas considerações (propostas de leitura) sobre específicos e importantes textos legais diretamente relacionados à atividade decisória. Para tanto, como metodologia, recorre-se ao "método" fenomenológico-hermenêutico

Desse modo, o presente artigo é divido em três partes: primeiramente, tecemos considerações acerca da importância dos paradigmas filosóficos para a compreensão do papel das decisões jurídicas no âmbito do Direito. Com isso, num segundo momento, é apresentada a forma como as decisões judiciais são proferidas no caso brasileiro. Por fim, com base no quadro apresentado e de acordo com a importância dos paradigmas filosóficos para o enfrentamento do tema, buscou-se apresentar algumas formas de leitura sobre textos legais essenciais no que tange às decisões jurídicas.

\section{DECISÕES JURÍDICAS, PARADIGMAS FILOSÓFICOS E DEMOCRACIA}

Não se pode negar que há importante doutrina que não atribui ao Poder Judiciário um papel de preponderância em democracias. Isso porque há concepções que apostam na ideia de predominância do Poder Legislativo enquanto Órgão de representação das maiorias na condução dos assuntos importantes da sociedade. Com efeito, um autor referência desse posicionamento - Jeremy Waldron - não está convencido de que os “[...] tribunais, com suas perucas e cerimônias, seus volumes encadernados em couro e seu relativo isolamento ante a política partidária, sejam um local mais adequado para solucionar questões desse caráter." (WALDRON, 2003, p. 05). Inclusive, o autor lança uma observação crítica no que tange às decisões tomadas pelas Cortes em face das leis votadas pelo Legislativo, que são o produto do trabalho dos representantes eleitos (WALDRON, p. 2014)such as the U.S. Supreme Court, make important decisions about rights by voting, and often the decision is determined by a bare majority. But the principle of majority decision (MD.

Observe-se que, não obstante ser um autor positivista, Waldron denuncia o interesse dos positivistas modernos pelo direito que é desenvolvido nos tribunais, em vez de focarem seus esforços na legislação que, por tradição, para o positivismo jurídico, era a base do direito (WALDRON, 2003). Portanto, o autor assume uma postura crítica ao papel contramajoritário das Cortes, defendendo a dignidade da legislação. Seu diagnóstico é que "As pessoas convenceram-se de que há algo indecoroso em um sistema no qual uma legislatura eleita, dominada por partidos políticos e tomando suas decisões com base no governo da maioria, tem a palavra final em questões de direito e princípios". (WALDRON, 2003, p. 05). Sua proposta é uma teoria da legislação, em que defende o princípio majoritário de democracia.

Em que pese as considerações a favor do sistema majoritário, este trabalho parte do pressuposto de que a democracia não deve ser concebida apenas sobre o prisma das maiorias estabelecidas nas eleições, porquanto, a rigor, o conceito de democracia deve agregar elementos mais amplos. Conforme Abboud (2019, p. 1251) a democracia não "[...] pode ser transmutada apenas em sinônimo de maioria. O motivo é simples: a maioria degenera." É nesse contexto que deve ser pensado o papel do Poder Judiciário 
nas democracias, inclusive com base em diagnóstico sobre a transformação no Direito pós Segunda Grande Guerra com a predominância de um constitucionalismo em nível global (ACKERMAN, 1997). Isso significa que existe, de fato, uma aproximação entre constitucionalismo e democracia (STRECK, 2017). Com efeito, o constitucionalismo apresenta um paradoxo em que é forjada a própria ideia de jurisdição constitucional (STRECK, 2017) porquanto a constituição “[...] do mesmo modo que surge como exigência para conter o poder absoluto do rei, transforma-se em um indispensável mecanismo de contenção do poder das maiorias." (STRECK, 2017, p. 111).

Com isso, a história atual evidencia os aspectos estruturantes do constitucionalismo na organização social e, portanto, atrai para o Poder Judiciário importante papel no compromisso democrático, a ser norteado pelas constituições enquanto documentos escritos que impõe parâmetros com força normativa. Conforme Hesse (1991), a força da constituição está relacionada à própria convicção que se tem acerca da própria inviolabilidade da constituição e em razão da força que essa convicção exerce sobre os atores que são os principais responsáveis pela vida constitucional.

Enfim, o que se pretende demonstrar como pressuposto básico para o desenvolvimento deste trabalho é que a noção de democracia convive com o constitucionalismo e, assim, com a ideia de jurisdição constitucional. É necessário registrar, então, que os textos constitucionais, desde a Constituição americana e, na Europa, com a constituição de Weimar, possuem uma dimensão marcadamente democrática. (ABBOUD, 2019).

Dessa forma, mostra-se inarredável uma teoria da decisão como elemento essencial para a consolidação da democracia (STRECK, 2017), o que significa um constante apelo à observação e crítica acerca de como as Cortes tomam decisões. Não se pode olvidar que é fato que o papel do Poder Judiciário em relação às questões sociais, e mesmo com a política, tem se espraiado com intensidade nos últimos tempos (TRINDADE, OLIVEIRA 2016)que cresceu na última década. O artigo tem como pano de fundo a crise política que se instalou no Brasil entre os anos de 2014 e 2015 e está baseado na seguinte hipótese de trabalho: quanto maior o grau de paralisação do sistema político maior o grau de provocação para que o judiciário decida sobre toda a sorte de tema controverso. A análise é organizada em três partes coordenadas: $\left(a^{1}\right.$.

Nessa perspectiva, decisões jurídicas, sob o ponto de vista da democracia, devem estar devidamente fundamentadas e respaldadas na Constituição. Assim, para um correto adentrar nesse campo da teoria da decisão, é imprescindível uma indagação sob o ponto de vista da filosofia, já que é por intermédio desse pressuposto que se pode conceber o habitus que condiciona o exercício das Cortes. A questão atrai uma reflexão crítica sobre o exercício da aplicação do direito - notadamente o Direito é construído pelos mais diversos atores, mas o trabalho se concentra nos atos que expressam decisões jurídicas (os atos dos magistrados, enfim) -, e o cerne da questão corresponde ao fato de que a concepção filosófica importa sobremodo para saber como as Cortes resolvem as questões jurídicas.

Diante desse quadro, o diagnóstico streckniano sobre a permanência do paradigma positivista no Direito brasileiro é capaz de lançar luz sobre os problemas em torno das decisões judiciais e, nesse sentido, sua desvinculação, não raro, com o pressuposto democrático. É claro que o positivismo jurídico

1 Em que pese tal fenômeno esteja mais fortemente atrelado com tribunais que desempenham uma função estratégica na interpretação da Constituição, tal fato não afasta o fenômeno em relação a outros âmbitos do Poder Judiciário. Sobre este tema, ver também: TASSINARI, Clarissa. Jurisdição e ativismo judicial. Limites da atuação do Judiciário. Porto Alegre: Livraria do Advogado, 2012. 
não se resume a apenas uma forma simples de entender o Direito ligado simplesmente à aplicação pura da lei, isso porque, em verdade, o positivismo jurídico é algo complexo (STRECK, 2020). Nesse sentido, por exemplo, Abboud, Carnio e Oliveira (2009) ressaltam a profunda diferença existente entre um tipo de positivismo jurídico que foi praticado no século XIX (positivismo legalista) de outro tipo que foi predominante no século XX (positivismo normativista kelseniano). Além disso, após Hart, surgiram o que podemos chamar de tipos de positivismo moderno, denominados de positivismo inclusivo e positivismo excludente (SHAPIRO, 2007).

Sem dúvida, a obra de Hart marca um ponto importante na Teoria do Direito, não apenas pela relevância intrínseca do seu trabalho, mas, igualmente, pelo fato de que, a partir de suas teses, nasceram os debates mais interessantes nessa área, notadamente com as considerações que Dworkin teceu à teoria hartiana. No âmbito do positivismo jurídico Hart dá um passo para além dos autores anteriores e centra sua teoria na questão da regra social e a importância que a aceitação dos envolvidos têm para a compreensão do Direito, bem como a ideia de atitude crítica reflexiva (MICHELON, 2004). A importância e novidade apresentada por Hart, à evidência, tem respaldo no uso da filosofia da linguagem. Isso significa que o autor transcende uma abordagem ancorada em fatos brutos (dimensão fisicalista) e retira da filosofia da linguagem ordinária uma maneira de perceber a prática dos participantes como essencial ao entendimento sobre O Conceito de Direito (MICHELON, 2004). É sob esse aspecto que Francisco Motta (2018) aduz que essa proposta hartiana “[...] é um verdadeiro ponto de inflexão teórica, tanto para o positivismo jurídico, como para seus críticos.”

Conquanto relevante e inovadora, há uma questão que ainda persiste na teoria de Hart, e que também atinge toda a teoria positivista pós-kelseniana, que é a falta de uma teoria da decisão, a qual se expressa inexoravelmente como possibilidade de discricionaridade do julgador. Em verdade, Lenio Streck (2017a), com propriedade, refere que há uma continuidade do problema paradigmático-filosófico em Hart, porquanto, a despeito de uma objetividade quando descreve o Direito "[...] nos casos em que há uma textura aberta da linguagem jurídica, o juiz pode interpretar o Direito de forma discricionária, ainda que com as ressalvas da parcimônia." (STRECK, 2017a, p. 163).

Ora, as referidas constatações são absolutamente pertinentes para a compreensão e desenvolvimento de raciocínios sobre um entendimento da relação entre democracia e decisões judiciais, visto que a perspectiva filosófica é fundante do que ocorre na prática. Não é possível perscrutar acerca da atividade decisional apenas sob o ponto de vista dos resultados, pois, antes disso, há uma dimensão filosófica que anima o agir. Desse modo, é inarredável uma abordagem que leva em consideração as influências mais amplas sobre o agir dos magistrados.

Dessa forma, a partir de uma concepção metaética sobre as formas de pensamento sobre o jurídico, Ferreiro Neto (2015) apresenta o positivismo jurídico como uma corrente de pensamento não cognitivista moral. ${ }^{2}$ Dessa forma, o que se pretende chamar a atenção é que o positivismo não pode ser encarado como um fenômeno único e que ele é essencial para compreender a ratio que perpassa qualquer tentativa de pensar a atuação jurídica, destacando-se o caso brasileiro neste trabalho. É nessa perspectiva que cabe observar o seguinte argumento:

2 O autor também apresenta, resumidamente, os princípios fundantes do Neopositivismo que também são pressupostos metaéticos relacionados ao positivismo jurídico. 
Como se pode perceber, ao longo da história o juspositivismo tem passado por várias readaptações que possibilitaram sua sobrevivência - com muito vigor - até os dias de hoje. É preciso especial cuidado por parte da teoria do Direito, para evitar que se critique sua caricatura. A teoria do Direito deve, assim, impedir que o positivismo continue a ser interpretado dicotomicamente e, de outro lado, continuar disfarçando no discricionarismo do intérprete uma espécie de viés superador do exegetismo clássico. Nada mais equivocado, uma vez que apenas estar-se-á substituindo um vetor de sentido (a lei) pelo proprietário dos sentidos da lei (o juiz-intérprete), culminando, no mais das vezes, em um realismo jurídico tardio, que nada mais é do que uma forma de positivismo, só que fático. (STRECK, 2020, p. 336).

Mas a questão paradigmática verdadeiramente de fundo diz respeito, numa concepção filosófica, à insistência sobre as potencialidades do solipsismo próprio da modernidade, que tem o indivíduo como o arauto da racionalidade e onde o método pretende oportunizar as respostas aos desafios que se busca desvendar (STRECK, 2018). É aqui que está assentada a forma que impacta a prática forense e a teoria que se produziu nos últimos tempos 3 . Com efeito, "A partir dessa ontologische Wendung, inicia-se o processo de superação dos paradigmas metafísicos objetivista (aristotélico-tomista) e subjetivista (filosofia da consciência), os quais, de um modo ou de outro, até hoje têm sustentado, de um lado, as teses exegético-dedutivistas-subsuntivas dominantes naquilo que vem sendo denominado de hermenêutica jurídica [...]." (STRECK, 2010, p. 159).

Neste ponto, a Crítica Hermenêutica do Direito, que amálgama a hermenêutica filosófica gadameriana com o interpretativismo dworkiniano oferta pressupostos para pensarmos na construção de uma teoria da decisão capaz de congregar o compromisso democrático e constitucional. Isso porque, ao mesmo tempo que diagnostica a falha do positivismo - e da filosofia motriz da modernidade, a CHD busca propor uma ruptura paradigmática nesse sentido, salientando a necessidade de decisões constitucional e democraticamente amparadas, e construídas na intersubjetividade.

\section{UM BREVE DIAGNÓSTICO SOBRE AS DECISÕES JURÍDICAS - O CASO BRASILEIRO}

No que concerne ao cenário das decisões jurídicas no Brasil, cabe ressaltar, de início, que se está tratando de um sistema em que o Direito foi estruturado a partir do paradigma da codificação de influência europeia-continental, dentro da tradição romano-germânica (DAVID, 2014), o que acarreta a forma pela qual deve ser analisada a prática decisional brasileira. Sob essa influência, é possível observar que a prática e a teoria jurídica brasileiras são permeadas por um dogmatismo estrutural que se retroalimenta entre doutrina e a vida forense. Nesses termos, o Direito brasileiro foi diretamente influenciado por uma ciência dogmática que, nas palavras de Ferraz Junior (2016, p.56) é construída [...] como um processo de subsunção dominada por um esquematismo binário, que reduz os objetos jurídicos a duas possibilidades: ou se trata disso ou se trata daquilo, construindo-se enormes redes paralelas de seções.”

O fato é que esse círculo em que o jurídico transita no Brasil, da teoria à prática, esteve (e continua) associado com uma dogmática que não dá conta de compreender o Direito na sua complexidade.

3 Neste ponto, cabe destacar a influência do paradigma da subjetividade próprio da modernidade, que tem suas consequências na própria concepção de compreender os fenômenos. Assim, Streck e Matos destacam que (Lenio Luiz Streck and Matos 2014) “Juntamente como isso, é necessário pensar sobre o paradigma da subjetividade desenvolvido na Modernidade que, ainda preso na relação gnosiológica sujeito-objeto, alterou significativamente o modo do homem se relacionar com o mundo. Outrora assujeitado numa realidade de verdades dogmaticamente predeterminadas - o que permite uma equiparação entre o direito e a lei que representava a vontade geral e "dava" conta de todas as situações fáticas - passa a assujeitar os sentidos". 
Com efeito, o modelo teórico que é emprestado à tomada de decisões pelos intérpretes parte de um pressuposto de possibilidade de “[...] pretensão de totalidade de apreensão de sentidos do texto", bem como no manejo de "[...] métodos que garantam a objetividade e preservem o sentido do texto atribuído por seu autor". (ABBOUD, CARNIO e OLIVEIRA, 2009, p. 503). Contudo, tal "fórmula" não entrega decisões democraticamente construídas. Esse é o cenário, de forma bastante ampla, que congrega a forma que é dada à experiência decisional brasileira. Ou seja, as decisões, em sua regra, são tomadas dentro de um ambiente de insuficiência face à riqueza do fenômeno jurídico, nada obstante sua utilização seja no sentido de conferir um verniz de objetividade às decisões.

Esse contexto apresentado lança luz sobre a forma de pensamento compartilhado pelos juízes brasileiros, não obstante a existência de uma Constituição que impõe balizas para a função judicial, com a necessidade de fundamentação das decisões, sob pena de nulidade. Nesse sentido, em verdade, há a criação de um discurso tendente a dar credibilidade à decisão, porém isso não quer significar necessariamente que a prestação jurisdicional ocorra de forma devidamente amparada no Direito.

Nesse aspecto, Rodriguez (2013) denomina de zona de autarquia aquele espaço em que as decisões são tomadas à revelia de fundamentação, ou seja, sem qualquer padrão de racionalidade a nortear como os magistrados julgam. Importante que se diga, conforme ressaltado pelo autor, que dificilmente existirá uma confissão expressa no sentido de que a autoridade proferirá sua decisão deixando claro que não utiliza padrões de racionalidade. Esse ponto é fundamental. Cabe à doutrina (nesse sentido também caberia aos agentes do Ministério Público e advogados, por exemplo) buscar descobrir (tirar o que cobre) a própria estrutura da decisão. Afinal, "É de se esperar que esteja presente alguma forma de falsa fundamentação cujo objetivo seja conferir aparência racional a decisões puramente arbitrárias”. (RODRIGUEZ, 2013, p. 70).

É preciso deixar claro que, sob este aspecto, as decisões ganham (quando ganham) um manto de tecnicidade ou objetividade mas, não raro, traduzem-se em julgamentos reveladores de idiossincrasias puras. Aqui sim há uma violação em termos democráticos. Conforme exposto anteriormente, a crítica que se dá quanto à atuação do judiciário frente ao Poder Legislativo pode ser no que diz respeito à falta de legitimidade popular dos integrantes do poder judiciário, razão que já dissemos não ser sustentável sob o ponto de vista do Constitucionalismo Contemporâneo. Contudo, isso não quer significar que as decisões do judiciário sejam livres, no sentido de representar desejos pessoais dos magistrados. Aqui é que há razão para a crítica sob o ponto de vista democrático. Não se está querendo impor aos magistrados um julgamento simplesmente mecânico, até porque o Direito, como já dito, em razão de sua complexidade, requer uma abordagem no mesmo nível. Desse modo é que se mostra pertinente quando Francisco Motta (2018, p. 280) alerta, acertadamente, para “[...] a importância de que uma teoria da decisão jurídica traga uma preocupação com a filosofia moral”. Mas isso não significa decisões morais do magistrado.

Para expor com ainda mais elementos como são construídas as decisões, no caso brasileiro, deve-se destacar o caráter da pessoalidade que subjaz o fenômeno. Um exemplo extremo que denuncia essa natureza é apresentado por José Rodrigo Rodriguez ao descrever que, mesmo em decisões em que está presente a participação de terceiros (como audiências públicas e amici curiae, por exemplo) fato que deveria encarar uma noção democraticamente integradora -, há a predominância do caráter 
pessoal. Note-se que a autoridade, mesmo nessas circunstâncias em que é permitida a participação de terceiros “[...] mantém o controle subjetivo sobre a decisão e porta-se como um indivíduo que precisa ser convencido e não como o representante de uma instituição cuja função é investigar o direito posto para encontrar os melhores argumentos jurídicos". (RODRIGUEZ, 2013, p. 76).

Diante dessas constatações apresentadas, importa também lembrar, nessa parte do trabalho que se dedica a expor a forma de atuação do judiciário brasileiro, a questão atinente ao ativismo judicial, fenômeno que tem se mostrado bastante comum ${ }^{4}$. Por ativismo entende-se o atuar do julgador fora dos limites do Direito, lançando mão de sua própria subjetividade para decidir e, conforme Georges Abboud (2019, p. 1323) "[...] toda decisão judicial ativista é ilegal e inconstitucional. Por conseguinte, o ativismo judicial, em aspectos funcionais, caracteriza atuação insidiosa do Poder Judiciário em relação aos demais poderes [...]”. Nesse aspecto, à toda evidência, uma decisão ativista é antidemocrática. Como bem lembrado pelo autor, há uma negação do código lícito/ilícito, que caracteriza o Direito (ABBOUD, 2019).

Certo que a ideia de ativismo não deve ser confundida com judicialização da política. Embora em ambos há relação entre as ações do judiciário frente aos demais poderes, sobretudo no que tange à relação com o Poder Legislativo, tais ações são diferentes e têm um impacto igualmente diverso no que diz respeito à democracia ${ }^{5}$. É nesse sentido que Anderson Vichinkeski Teixeira (2020) destaca o ativismo como uma patologia constitucional contemporânea que se apresenta como um desafio à própria democracia liberal. Como vimos, em termos democráticos a decisão judicial permeada de subjetivismo, que se expressa do modo ativista, deve ser barrada. As consequências desse ranço da subjetividade no modo de decidir está bem ilustrada, como segue:

Na verdade, o drama da discricionariedade que venho criticando de há muito é que esta transforma os juízes em legisladores. E mais do que transformar juízes em legisladores, o "poder discricionário" propicia a "criação" do próprio objeto de "conhecimento", típica problemática que remete a questão ao solipsismo característico da filosofia da consciência no seu mais exacerbado grau. Ou seja, concebe-se a razão humana como "fonte iluminadora" do significado de tudo o que pode ser enunciado sobre a realidade. Nesse paradigma, as coisas são reduzidas aos nossos conceitos e às nossas concepções de mundo, ficando à disposição de um protagonista (no caso, o juiz, enfim, o Poder Judiciário). E isso acarreta consequências graves ao Estado Democrático de Direito. (STRECK, 2013, p. 594).

\footnotetext{
4 Sobre uma contextualização temporal, pode-se dizer, com Trindade e Oliveira (2016)que cresceu na última década. O artigo tem como pano de fundo a crise política que se instalou no Brasil entre os anos de 2014 e 2015 e está baseado na seguinte hipótese de trabalho: quanto maior o grau de paralisação do sistema político maior o grau de provocação para que o judiciário decida sobre toda a sorte de tema controverso. A análise é organizada em três partes coordenadas: (a que o "passivismo judicial" foi abando progressivamente após a Constituição de 88 . Nesse contexto, conforme os autores "No Brasil, especialmente a pós a ressaca que marcou a primeira década que sucedeu à promulgação da Carta de 1988 e, ainda, a etapa da assimilação da necessidade de uma filtragem hermenêutica-constitucional dos direitos, a discussão acerca do papel do Poder Judiciário tornou-se uma pauta constante nas discussões jurídico-políticas, com o abandono do passivismo jurídico." (TRINDADE, Oliveira, 2016, p. 761)que cresceu na última década. O artigo tem como pano de fundo a crise política que se instalou no Brasil entre os anos de 2014 e 2015 e está baseado na seguinte hipótese de trabalho: quanto maior o grau de paralisação do sistema político maior o grau de provocação para que o judiciário decida sobre toda a sorte de tema controverso. A análise é organizada em três partes coordenadas: (a

5 Sobre o tema ativismo judicial e judicialização da política, por todos, é imprescindível a explicação de Streck (2017b, p. 87): "Assim, é preciso diferenciar o ativismo judicial da judicialização da política, questão que no Brasil foi examinada com pouca profundidade, como se os fenômenos tratassem da mesma coisa. Essa dificuldade conceitual deve ser enfrentada, especialmente porque vivemos sob um regime democrático, cujas consequências do ativismo podem ser muito prejudiciais. É nesse sentido que é possível afirmar que a judicialização da política é um fenômeno, ao mesmo tempo, inexorável e contingencial, porque decorre de condições socio-políticas, bem como consiste na intervenção do judiciário na deficiência dos demais poderes. Por outro lado, o ativismo é gestado no interior da própria sistemática jurídica, consistindo num ato de vontade daquele que julga, isto é, caracterizando uma "corrupção" na relação entre os Poderes, na medida em que há uma extrapolação dos limites na atuação do judiciário pela via de uma decisão que é tomada a partir de critérios não jurídicos.".
} 
Observa-se que a identificação do ativismo, para os fins aqui proposto, merece ser realizada a partir de uma análise qualitativa, uma vez que "É na interpretação e na fundamentação, portanto, que reside o problema." (TRINDADE, OLIVEIRA, 2016, P. 762)que cresceu na última década. O artigo tem como pano de fundo a crise política que se instalou no Brasil entre os anos de 2014 e 2015 e está baseado na seguinte hipótese de trabalho: quanto maior o grau de paralisação do sistema político maior o grau de provocação para que o judiciário decida sobre toda a sorte de tema controverso. A análise é organizada em três partes coordenadas: (a.

Além disso, é preciso ressaltar, também, que a irracionalidade enquanto padrão que segue a atividade de julgar, no caso brasileiro, expressa-se na sua vertente individual (juiz singular) e também quando pronunciada por tribunais (RODRIGUEZ, 2013). Aliás, em sede de tribunais, a forma como são disponibilizadas as decisões tendem a gerar inclusive mais obstáculos para o que se tem como um padrão democrático a ser seguido ${ }^{6}$. Porém, a questão é que o Direito deve ser o elemento que tem o papel de dar sustentação ao sistema como um todo. E é em razão disso que o Direito não pode se formar a partir de uma atividade em que a "discricionariedade" é a regra quando se fala em decisões jurídicas.

Há um forte descompasso existente, portanto, entre o que se espera de decisões jurídicas, a partir de um pressuposto democrático, e aquilo que é encontrado na prática dos tribunais. Todavia, numa perspectiva civilizatória concernente à democracia liberal, a Constituição se impõe como marco primeiro para fins de fundamentação nas decisões judiciais.

Lenio Streck e Gilberto Morbach (2019) desenvolvem interessante debate sobre desacordos morais próprios das sociedade atuais, que são perpassadas por uma genuína complexidade, e o papel do Direto como fator fulcral diante desses disagreements. O permanente estado de desacordos tem impacto direto nas resoluções judiciais. Nesse ponto, conforme referem os autores, deve ser ressaltada a importância da autonomia do Direito, isso porque "[...] nenhuma resposta satisfatória pode vir do emotivismo jurídico." (STRECK, MORBACH, 2019, p. 284).

Com efeito, não é o fato de o Direito ter “[...] uma relação autoevidente com a interpretação"(RAATZ, DIETRICH, MORBACH, 2018, p. 336) e em razão de a "A indeterminação ser conatural ao Direito [...] " (RAATZ, DIETRICH, MORBACH, 2018, p. 367) que os juízes estejam livres para impor suas visões de mundo no seu ato decisional. Ora, não encontra esteio constitucional a transferência de poderes aos juízes para estes imprimirem conclusões valorativas no mister jurisdicional apenas pelo fato de ser inexorável os desacordos em sociedade; por existir uma relação íntima entre direito e interpretação e por ser inescapável a vagueza natural da linguagem. Na verdade, é em razão disso que deve haver um controle das decisões judiciais, tendo em vista que o Direito deve ser pronunciado em detrimento de considerações pessoais.

É justamente nesse aspecto uma das mais fortes críticas de autores pós-positivistas como Ronaldo Dworkin, que entende haver Direito naqueles espaços em que o positivismo permite a discricionariedade no ato de julgar. Isso significa uma crítica aguda de Dworkin à discricionariedade, já que o autor entende o Direito numa perspectiva de integridade. (DWORKIN, 2014). Ademais disso, é por intermédio

6 Nesse sentido, Rodriguez (2013, p. 83) aduz que “[...] o Tribunal não organizará a decisão de maneira unificada. Limitar-se-á a publicar todas as opiniões dos juízes em conjunto e sem hierarquia, incluindo a transcrição dos debates ocorridos na sessão de julgamento, intercalados com os votos apresentados por escrito, que são elaborados com antecedência. O documento resultante, quase sempre longo, desorganizado e difícil de manusear, é um retrato fiel do processo decisório em que vence o caso aquele que convencer individualmente mais juízes. Os demais tribunais brasileiros repetem o mesmo padrão." De fato, o diagnóstico apresentado pelo autor é uma praxe dos tribunais, que não buscar dar um mínimo de coerência a seus julgados, fator que prejudica o caráter democrático das decisões. 
dos princípios que o Direito se concretiza de forma plena ${ }^{7}$. Nesse novo panorama de pensamento em que o Direito se insere, pois, não há mais lugar para a defesa de uma forma de julgar alheia ao que é compartilhado como "direito de fundo", construído argumentativa e fundamentadamente. Os princípios jurídicos, nesse sentido, têm um papel central na construção democrática das decisões jurídicas, uma vez que "[...] o juiz inserido nessa comunidade política deverá adequar sua decisão ao sentido mais coerente com a prática jurídica daquela comunidade democrática, ou seja, ele tem um vínculo jurídico, democrático e histórico que o orienta na ação de decidir, isto é, na criação do ius." (LORENZONI,

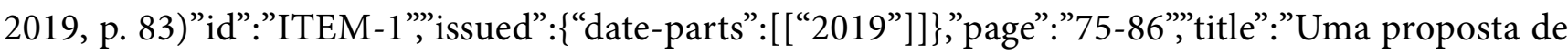
genealogia dos princípios: síntese de algumas contribuições filosóficas para uma adequada compreensão dos princípios jurídicos",'type":"article-journal"\},"uris":[“http://www.mendeley.com/documents/?uuid=ff64894d-8c7d-4215-a87d-4a4abc1ba0db"]\}],"mendeley":\{“formattedCitation":"(Lorenzoni 2019

Ocorre que, conforme largamente denunciado por Streck, o caso brasileiro foi inundado por uma forma de julgar com base na criação de "princípios" que, em verdade, não passam de estratagemas argumentativos para decidir a partir de razões individuais. No dizer do jurista gaúcho, "Positivaram-se os valores": assim se costuma anunciar os princípios constitucionais, circunstância que facilita a 'criação', em um segundo momento, de todo tipo de 'princípio', como se o paradigma do Estado Democrático de Direito fosse a pedra filosofal da legitimidade principiológica [...]”. (STRECK, 2017b, p. 555). Ou seja, esse fenômeno, visivelmente constatado na prática jurídica, está a desafiar a construção de decisões com respaldo no direito compartilhado na comunidade e que requer, do intérprete, a demonstração fundamentada das soluções. De fato, a superação do positivismo jurídico não pode ocorrer sem que se supere o entendimento dos princípios como algo que leve à "abertura" (STRECK, 2017b), como parece ser a tônica a embalar as práticas dos tribunais pátrios. Esse ponto é fundamental para a construção de uma Teoria da Decisão comprometida com a democracia. Fundamentalmente, a discussão concernente às decisões jurídicas deve ter presente uma forma de naturalização dessa prática, a qual manifesta-se à revelia da verdadeira necessidade de concretização do direito, com a invenção de toda sorte de princípios. Nesses termos:

[...] não é possível inventar um princípio a cada momento, como se no Direito não existisse uma história institucional a impulsionar a formação e a identificação dos princípios. Princípios utilizados de maneira ad hoc para solucionar pseudoproblemas não são princípios, porque, tanto quanto é correto dizer que os princípios só são concretamente - vale dizer, na apllicatio -, é também correta a afirmação de que princípios não existem sem a historicidade do Direito. Se é certo que os princípios são a história institucional do Direito, eles não cabem dentro de uma concepção instantaneísta de tempo; eles não podem ser 'criados' a partir de graus zeros de sentido. (STRECK, 2017b, p. 618).

\section{ALGUMAS PROPOSTAS PARA A DEMOCRATIZAÇÃO DAS DECISÕES JURÍDICAS}

Destacamos acima, primeiramente, a necessidade de ter em consideração a importância que os paradigmas filosóficos têm para a compreensão do Direito e, no particular, como isso permite conhe-

\footnotetext{
7 A questão é que Dworkin está preocupado com “direitos de fundo", que vão além dos textos jurídicos, mas que estão ancorados nos próprios princípios autênticos do Direito. Conforme o jusfilósofo norte-americano (DWORKIN, 2019, p. 15), "Pois o ideal da prestação jurisdicional, no modelo centrado nos direitos, é de que, na medida em que isso é praticável, os direitos morais que os cidadãos efetivamente possuem devem ser acessíveis a eles no tribunal. Portanto, uma decisão que leva em conta direitos de fundo será superior, do ponto de vista desse ideal, a uma decisão que, em vez disso, especula, por exemplo, sobre o que o legislador teria feito se houvesse feito alguma coisa."
} 
cer com mais clareza a natureza das decisões jurídicas, de acordo com o paradigma em que elas são realizadas. Após, dedicamos um espaço para descrever como as Cortes e os juízes decidem no Brasil, de uma maneira geral, a partir do referencial teórico previamente apresentado e com base em pesquisa bibliográfica dedicada ao estudo. Enfim, buscamos estabelecer nesses dois primeiros espaços um diagnóstico da prática forense, sob o prisma da influência do imaginário existente dentre os encarregados pela tomada de decisões no sistema jurídico brasileiro.

Assim, cabe agora, sem a pretensão de esgotar o tema (tendo em vista e sua complexidade e espaço deste artigo) destacar algumas propostas que podem favorecer a democratização das decisões jurídicas.

Antes de qualquer consideração sobre textos legais que estão diretamente ligados às decisões judiciais - para os fins deste artigo vamos concentrar nos principais artigos do Código de Processo Civil sobre decisão judicial e no artigo 20 da LINDB -, cabe anotar que a obrigatoriedade sobre decisões jurídicas democráticas tem seu lugar, antes de tudo, nos próprios fundamentos do "Constitucionalismo Contemporâneo" e, no particular, a Constituição de 88 é bastante em si sobre o dever de fundamentação e publicidade das decisões judiciais.

O ponto fundamental aqui, e já tratado na primeira parte deste trabalho, diz respeito à legitimidade do Poder Judiciário enquanto poder democrático, e isso implica que este poder pode ser concebido de uma forma democrática quando assume a responsabilidade política por decidir no nível dos princípios e em consonância com o documento que constitui o Estado e os Direitos Fundamentais - a Constituição. Afinal, aqui está a ideia do "Fórum de princípio" dworkiniana, ambiente em que o Judiciário exerce a legitimidade democrática de sua função ${ }^{8}$. Consequência direta disso, portanto, é o dever de negação a qualquer prática decisionista. A possibilidade de participação do judiciário em decisões importantes da comunidade impõe responsabilidade política de autocontenção9

Daí a importância do dever de fundamentação enquanto elemento primordial no Estado Democrático de Direito. Isso significa que aquele que decide deve observar o Direito compartilhado pela comunidade jurídica e expor os fundamentos de sua decisão de forma clara e de acordo com as normas - aqui incluídas tanto as regras quanto os princípios. Aliás, os princípios exsurgem no Direito como um padrão de "fechamento" da decisão e não como abertura, como tem sido a praxe em decisões judiciais (STRECK, 2020). Isso significa dizer que os princípios devem ser compreendidos, à luz da normatividade, como elementos que funcionam para o fechamento na concretização do direito, não podendo mais ser encarados como "janelas" que permitem abertura para valores externo ao Direito. A crítica streckiana é contra o uso indiscriminado de "princípios", o que, em hipótese alguma, afasta a importância que os princípios assumem na concretização do direito. Ao contrário disso, os princípios autênticos compartilhados na comunidade jurídica têm o papel de confirmar a autonomia do Direito na fundamentação das decisões.

\footnotetext{
8 Conforme Dworkin, o debate que lança luz sobre o papel da revisão judicial é valioso. Nas palavras do autor: "A revisão judicial assegura que as questões mais fundamentais de moralidade política serão finalmente expostas e debatidas como questões de princípio e não apenas de poder político, uma transformação que não pode ter êxito - de qualquer modo, não completamente - no âmbito da própria legislatura. Isso é mais importante que as efetivas decisões a que se chegam nos tribunais com essa incumbência. A revisão judicial é uma característica distintiva de nossa vida política, invejada e cada vez mais copiada em outros lugares. É uma característica penetrante porque obriga o debate político a incluir o argumento acerca do princípio, não apenas quando um caso vai ao tribunal, mas muito antes e muito depois. Esse debate não é necessariamente muito profundo nem é sempre muito vigoroso. É, não obstante, valioso". (DWORKIN, 2019, p. 102).

9 Conferir, especialmente, as seis hipóteses em que o juiz pode deixar de aplicar a lei, ou, em outras palavras, a necessidade de o juiz aplicar a lei quando não estiverem em jogo tais hipóteses. Para tanto, remete-se o leitor para o Verbete "Resposta Adequada à Constituição", em que o tema é proposto por Streck (2020).
} 
Portanto, dentro das vastas vias que um trabalho sobre decisão jurídica democrática pode abrir, após demarcarmos a importância da filosofia como paradigma de compreensão e da fotografia de como as Cortes brasileiras julgam, faremos um recorte em dois pontos que, atualmente, entendemos, são importantes no que tange à esfera de decisão. Trata-se do artigo 20 da LINDB e dos artigos do CPC diretamente ligados à decisão, e a importância de sua leitura a partir do paradigma da Crítica Hermenêutica do Direito e do interpretativismo dworkiniano, como forma de superação da velha dogmática e de uma aproximação de decisões jurídicas que sejam democraticamente construídas.

O enfoque aqui não está relacionado com os primeiros artigos da LINDB - sobretudo os artigos $4 .^{\circ}$ e $5^{\circ}$, que têm relação direta com a atividade jurisdicional, não obstante o fato de tais artigos estarem inseridos no paradigma já superado, como anteriormente tratado neste trabalho. Quanto à LINDB, a proposta, neste artigo, é analisar o artigo 20, que foi introduzido pela Lei n. 13.655/2018. Porquanto importante para a análise, cabe a reprodução do artigo: "Nas esferas administrativas, controladora e judicial, não se decidirá com base em valores jurídicos abstratos sem que sejam consideradas as consequências práticas da decisão". Para o escopo de uma teoria da decisão, mostram-se interessantes duas questões: "não se decidirá com base em valores jurídicos abstratos" e "sem que sejam consideradas as consequências práticas da decisão".

Ora, o que deve guiar a interpretação do referido artigo, que tem impacto profundo no Direito Público brasileiro, principalmente, é o fato de que não se pode desvincular interpretação da aplicação, como devidamente colocado pela Crítica Hermenêutica do Direito. Nesse sentido, a explicação que segue oferece um norte para a compreensão do artigo analisado:

\footnotetext{
Não percebemos de forma distinta (cindida), primeiro os textos para, depois, acoplar-lhes sentidos. Ou seja, na medida em que o ato de interpretar - que é sempre compreensivo/aplicativo - é unitário, o texto (pensemos, fundamentalmente, na Constituição) não está, e não nos parece, desnudo, como se estivesse à nossa disposição.

$[\ldots]$

A interpretação do Direito não é filologia. Há um mundo prático que se atravessa no processo de compreensão do Direito. Esse fenômeno é protagonizado pelos princípios constitucionais, que têm uma força fática - que resgata os sentidos que construímos na nossa interação cotidiana - e, com isso, diminui, na hora da aplicação, as múltiplas possibilidades de sentidos semânticos do texto. Não devemos esquecer que o texto não pode ser entendido em sua "textitude", devendo ser compreendido na applicatio, que não é uma “operação subsidiária”, mas a condição de possibilidade para que, do texto, construamos a norma. (STRECK, 2018, p. 75).
}

Com isso quer-se dizer que a previsão legal da LINDB aqui analisada não pode ser entendida como uma abertura para uma forma de consequencialismo puro, que desborda do campo do jurídico. O Direito, e sua autonomia, deve trabalhar com princípios, que são deontológicos, sob a perspectiva do paradigma defendido neste artigo. Até mesmo porque, respeitante aos princípios, "Eles institucionalizam o mundo prático [...]." (STRECK, 2020, p. 388). Mas isso não significa dizer que "considerar as consequências práticas da decisão" deva ser uma forma de abertura para elementos externos ao direito. $\mathrm{O}$ artigo 20 da LINDB deve ser compreendido à luz dos próprios princípios e da deontologia do Direito. A fundamentação é requisito inarredável de validade das decisões judiciais dentro da ordem constitucional-democrática. Ao contrário de qualquer defesa em relação à jurisprudência dos valores que poderia ser trazida à baila nesse contexto, faz-se necessário destacar, de forma clara, que o direito 
deve ser entendido sob a ideia de integridade e coerência (DWORKIN, 2014), tendo como base o fato da sua dimensão interpretativa, que requer fundamentação a partir da tradição jurídica. Apenas dessa forma é possível aceitar o texto analisado da LINDB. E é sob esse ponto de vista que ele pode ser útil para a construção de decisões democráticas, destacando-se que o artigo tem incidência não apenas no campo das decisões judiciais, mas também na tomada de decisões na esfera administrativa. Não se pode, com a ideia de querer afastar o uso de valores abstratos na tomada de decisão, acabar positivando a possibilidade de argumentos consequencialistas (econômicos?) à revelia da autonomia do Direito. Por isso que é importante compreender o conteúdo dos princípios. Os princípios não podem ser um álibi para qualquer tipo de decisão. Não. Ao contrário disso, os princípios devem instituir, normativamente, o próprio direito compartilhado na comunidade política. Se for entendido o real significado dos princípios, é possível afirmar que as decisões não serão tomadas com base em valores abstratos, porquanto, como já exposto, os princípios “institucionalizam o mundo prático", e isso significa o acompanhamento de densa fundamentação para a tomada de decisão, sobretudo quando acompanhado dos vetores do artigo 489 do Código de Processo Civil.

Portanto, tendo em vista a potencial relevância do art. 20 para as decisões jurídicas, entende-se que a leitura sugerida é aquela que melhor pode alcançar uma legitimidade democrática e constitucional.

Por outro lado, mas igualmente no âmbito da decisão judicial, tem-se que, não obstante entendamos que a Constituição Federal, por si só, já impunha todos os elementos para a obrigatoriedade de decisões judiciais democráticas, deve-se ressaltar que o Código de Processo Civil, de 2015, vem para tornar mais clara a obrigatoriedade da fundamentação das decisões, no sentido de concretizar a previsão constitucional. Também aqui, dentro de uma teoria da decisão que se impõe séria, entende-se que os desafios para a solução dos próprios problemas de política judiciária (destaca-se aqui o número de processos no Brasil) podem ser, no mínimo, atenuados, caso seja desenvolvida uma teoria da decisão capaz de formar um ambiente propício para decisões qualitativamente melhores, o que terá impacto não apenas no número de processos existentes, mas igualmente na concretização dos direitos dos jurisdicionados, o que significa uma aproximação dos compromissos da Constituição de 1988. Mas isso significa a adoção de uma ruptura com o paradigma que invadiu os tribunais pátrios, colocando-se no lugar uma leitura do CPC sob a luz do "Constitucionalismo Contemporâneo", e que a atividade jurisdicional seja controlada republicanamente - aqui a importância da accountability. Cabe anotar, por fim, como referido por Lenio Streck “[...] apontar o modelo adequado de decidir é tarefa da doutrina. Não há jurisprudência sem doutrina e a doutrina tem a tarefa de censura significativa das decisões." (STRECK, 2017b, p. 588).

Sob este aspecto, os artigos 926 e 489 do CPC são um verdadeiro marco acerca do dever de construção de decisões democráticas e, por isso, devem ser recepcionados sob os termos de um compromisso com a fundamentação das decisões, devendo ser controlada a formação de eventual jurisprudência defensiva que busque enfraquecer as conquistas da nova sistemática processual no que tange ao rigor a respeito da necessidade de decisões fundamentadas, íntegras, coerentes e adequadas à constituição, conforme largamente advogado pela Crítica Hermenêutica do Direito ${ }^{10}$. Nesse sentido, registra-se, ainda, o importante papel do Jurista Lenio Streck para o afastamento, no novo CPC, do Livre Conven-

10 Aliás, Lenio Streck, criador da CHD, teve papel importante na incorporação de novos marcos, como integridade e coerência - artigos 926 e 927 -, entre outros, ao Código Processual Civil, no sentido de realçar uma criteriologia decisional alinhada com o processo democrático. 
cimento Motivado, o que deve ser considerado outro marco importante para a superação de decisões jurídicas discricionárias.

Com base no que foi acima exposto, isso significa dizer que os textos legais referidos, em seu conjunto, consagram, no Direito brasileiro, o necessário dever de fundamentação das decisões judiciais, e devem permitir, concomitantemente, um maior controle sobre a tomada de decisões, garantindo-se a construção de julgamentos mais justos e democráticos.

\section{CONCLUSÕES}

A necessidade de uma teoria da decisão é inconteste para a concretização de uma Democracia. Essa questão está inarredavelmente relacionada aos paradigmas filosóficos que subjazem à teoria e prática dominantes. Nesse sentido, buscou-se neste trabalho, por um lado, identificar um retrato acerca da realidade brasileira respeitante ao processo decisório e, por outro, apresentar algumas possíveis propostas de leitura para o fortalecimento de decisões jurídicas que sejam democraticamente construídas.

De fato, como denuncia a doutrina crítica, o ambiente em que são proferidas as decisões jurídicas está envolto em uma tradição de déficit democrático, em que se sobressaem marcas de pessoalidade e subjetivismo, com prejuízo à segurança jurídica e, sobretudo, aos pressupostos caros ao Constitucionalismo Contemporâneo. Dessa forma, destacou-se a importância de as decisões jurídicas serem construídas com base no Direito e, assim, a fundamentação se impõe como forma de permitir o controle e a transparência das decisões jurídicas - accountability.

Especificamente, foram destacados dois pontos respeitantes à legislação que trata sobre o processo de decisão: a importância do artigo 20 da LINDB, em razão de sua potencial influência no ato de julgar (e por isso a necessidade de um olhar sob o ponto de vista da Crítica Hermenêutica do Direito); e, nessa mesma linha, uma visão dos principais artigos do Código de Processo Civil como vetores de fortalecimento democrático das decisões judiciais.

Neste ponto é importante destacar que os paradigmas filosóficos importam. É preciso que haja uma abertura para a recepção de um novo marco a pautar o processo decisional brasileiro, dentro da autonomia do Direito. A legislação já existe. Necessita-se, agora, que seja cumprida dentro dos paradigmas do Constitucionalismo Contemporâneo.

\section{CONFLITO DE INTERESSES}

"Não possui conflito de interesses".

\section{REFERÊNCIAS}

ABBOUD, Georges. Processo Constitucional Brasileiro. 3. ${ }^{a}$ ed. São Paulo: Thomson Reuters Brasil, 2019. ABBOUD, Georges; CARNIO, Henrique Carbellini; OLIVEIRA, Rafael Tomaz de. Introdução Ao Direito: Teoria, Filosofia e Sociologia Do Direito. 4. ed. São Paulo: Thompson Reuters Brasil, 2009. ACKERMAN, Bruce. The Rise of World Constitutionalism. Virginia Law Review, v. 83 n. 4, pp. 771 797, 1997. Disponível em: https://doi.org/10.2307/1073748. Acesso em 29/08/2020. 
DAVID, René. Os Grandes Sistemas Do Direito Contemporâneo. 8. a ed. São Paulo: Martins Fontes, 2014.

DWORKIN, Ronald. O Império Do Direito. 3. a ed. São Paulo: Martins Fontes, 2014.

DWORKIN, Ronald. Uma Questão de Princípio. São Paulo: Martins Fontes, 2019.

FERRAZ JUNIOR, Tércio Sampaio. Introdução Ao Estudo Do Direito: Técnica, Decisão, Dominação. 9. ${ }^{\text {a }}$ ed. São Paulo: Atlas, 2016.

FERREIRA NETO, Arthur Maria. Metaética e a Fundamentação do Direito. Porto Alegre-RS: Elegantia Juris, 2015.

HESSE, Konhad. A Força Normativa Da Constituição. Porto Alegre: Sergio Antonio Fabris Editor, 1991.

LORENZONI, Pietro Cardia. Uma Proposta de Genealogia Dos Princípios: Síntese de Algumas Contribuições Filosóficas Para Uma Adequada Compreensão Dos Princípios Jurídicos. Revista Da Faculdade de Direito do FMP, v. 14, n. 2, pp. 75-86, 2019. Disponível em: https://revistas.fmp.edu.br/ index.php/FMP-Revista/article/view/159. Acesso em: 20/08/2020.

MICHELON JR., Cláudio Fortunato. Aceitação e Objetividade: Uma Comparação Entre as Teses de Hart e Do Positivismo Precedente Sobre a Linguagem e o Conhecimento Do Direito. São Paulo: Editora Revista dos Tribunais, 2004.

MOTTA, Francisco José Borges. Ronald Dworkin e a Decisão Jurídica. 2 ed. rev. Salvador: Editora Juspodivm, 2018.

RAATZ, Igor; DIETRICH, William Galle; MORBACH, Gilberto. A Filosofia Da Linguagem Ordinária e a (inescapável) indeterminação do Direito." Rei - Revista Estudos Institucionais, v. 4, n.1, pp. 334-75, 2018. Disponível em: https://doi.org/10.21783/rei.v4i1.214. Acesso em 19-08-2020.

RODRIGUEZ, José Rodrigo. Como decidem as Cortes. 4 ed. Rio de Janeiro: Editora FGV, 2013.

SHAPIRO, Scott J. The 'Hart-Dworkin' Debate: A Short Guide for the Perplexed. 2007. Disponível em: https://papers.ssrn.com/sol3/papers.cfm?abstract_id=968657. Acesso em 18-08/2020.

STRECK, Lenio Luiz. 2013. Jurisdição e ausência de uma Teoria da Decisão, Revista de Derecho de la Pontificia Universidad Católica de Valparaíso, Valparaíso, n. 41, pp. 577-601, 2013. Disponível em: https://scielo.conicyt.cl/scielo.php?script=sci_arttext\&pid=S0718-68512013000200017. Acesso em: 16-08-2020.

STRECK, Lenio Luiz. Dicionário de Hermenêutica: Quarenta Temas Fundamentais Da Teoria Do Direito à Luz Da Crítica Hermenêutica Do Direito. Belo Horizonte: Letramento: Casa do Direito, $2017 \mathrm{a}$.

STRECK, Lenio Luiz. Verdade e Consenso. 6 ed. São Paulo: Saraiva, 2017b.

STRECK, Lenio Luiz. Hermenêutica e Princípios da Interpretação Constitucional. In: CANOTILHO, J.J. Gomes; STRECK, Lenio Luiz; MENDES, Gilmar Ferreira Mendes; SARLET, Ingo Wolfgang (org). Comentários à Constituição Do Brasil, 2. ed., São Paulo: Saraiva Educação (Série IDP), 2018, p. 73-89. 
STRECK, Lenio Luiz. Dicionário de Hermenêutica: 50 Verbetes Fundamentais Da Teoria Do Direito à Luz Da Crítica Hermenêutica Do Direito. 2 ed. Belo Horizonte: Letramento: Casa do Direito, 2020.

STRECK, Lenio Luiz. Aplicar a 'Letra Da Lei' é Uma Atitude Positivista?, Revista Novos Estudos Jurídicos, 15, p. 158-73, 2010. Disponível em: https://doi.org/http://dx.doi.org/10.14210/nej.v15n1. p158-173. Acesso em: 25-08-2020.

STRECK, Lenio Luiz; MATOS, Daniel Ortiz. Mitos Sobre o Positivismo Jurídico : Uma leitura ara além do senso comum teórico, v. 1, p. 120-40, 2014. Disponível em: http://revistasunifeso.filoinfo. net/index.php/revistaunifesohumanasesociais/article/view/10/16. Acesso em: 25-08-2020.

STRECK, Lenio Luiz; MORBACH, Gilberto. (Autonomia Do) Direito e Desacordos Morais, Revista Brasileira de Estudos Políticos, v. 253, n. 119, p. 253-89. Disponível em: https://doi.org/10.9732/p. 0034-7191.2019v119p253. Acesso em 20-08-2020.

TEIXEIRA, Anderson Vichinkeski. Tolerar o intolerável? três patologias constitucionais contemporâneas como desafios às democracias liberais. In: TEIXEIRA, Anderson Vichinkeski; JAQUES, Marcelo Dias; COPELLI, Giancarlo Montagner (org). Políticas Públicas No Brasil: Ensaios Para Uma Gestão Pública Voltada à Tutela Dos Direitos Humanos, Blumenau: Dom Modesto, 2020.

TRINDADE, André Karam; OLIVEIRA, Rafael Tomaz de. O Ativismo Judicial Na Débâcle Do Sistema Político: Sobre Uma Hermenêutica Da Crise, Revista Eletrônica Do Curso de Direito Da UFSM, v. 11, n. 2, p. 751-72, 2016. Disponível em: https://doi.org/10.5902/1981369422912. Acesso em: 28-08-2020. WALDRON, Jeremy. A Dignidade Da Legislação. São Paulo: Martins Fontes, 2003.

WALDRON, Jeremy. Five to Four: Why do Bare Majorities Rule on Courts?, Public Law \& Legal Theory Research Paper Series, n. 12-72, 2013. Disponível em: https://papers.ssrn.com/sol3/papers. cfm?abstract_id=2195768. Acesso em 19-08-2020. 